\title{
Chia (Salvia hispanica L.) Seed Oil Rich in Omega-3 Fatty Acid: A Healthy Alternative for Milk Fat in Ice Milk
}

\author{
Amany M. Basuny'1, Shaker M. Arafat², Dalia M. Hikal ${ }^{3 *}$ \\ ${ }^{1}$ Biochemistry Department, Faculty of Agriculture, Beni-Suef University, Beni Suef, Egypt \\ ${ }^{2}$ Oils \& Fats Research Department, Food Technology Research Institute, Agriculture Research Center, Giza, Egypt \\ ${ }^{3}$ Nutrition and Food Science, Home Economics Department, Faculty of Specific Education, Mansoura University, Mansoura, Egypt \\ Email: *dr.daliahikal@mans.edu.eg
}

How to cite this paper: Basuny, A.M., Arafat, S.M. and Hikal, D.M. (2021) Chia (Salvia hispanica L.) Seed Oil Rich in Omega-3 Fatty Acid: A Healthy Alternative for Milk Fat in Ice Milk. Food and Nutrition Sciences, 12, 479-493.

https://doi.org/10.4236/fns.2021.126037

Received: May 10, 2021

Accepted: June 7, 2021

Published: June 10, 2021

Copyright $\odot 2021$ by author(s) and Scientific Research Publishing Inc. This work is licensed under the Creative Commons Attribution International License (CC BY 4.0).

http://creativecommons.org/licenses/by/4.0/

\begin{abstract}
Chia seed oil (Salvia hispanica L.) contains polyunsaturated omega-3 fatty acids and natural antioxidants that have many health effects. Consequently, the chief purpose of the present study was the outcome of various attentiveness of chia seed oil on quality and sensory evaluation of ice milk. In treatments $T_{1}, T_{2}, T_{3}$, and $T_{4}$, the milk fat was moderately swapped with chia seed oil at $10 \%, 20 \%, 30 \%$, and $40 \%$, respectively, and compared with the control treatment $\left(100 \%\right.$ milk fat). All treatments were stored at $-18^{\circ} \mathrm{C}$ for 30 days. Samples were analyzed fortnightly and monthly to determine the shelf life during the storage period by acidity and peroxide value. Physicochemical properties of fatty acids, total polyphenols, and total flavonoids of chia seed oil and ice milk samples were determined. Also, the overrun and sensory evaluation of ice milk samples were studied. Results indicated an increase in the absorption of omega- 3 fatty acids (linolenic acid, eicosapentaenoic acid, docosapentaenoic acid, and docosahexaenoic "in the samples of" ice milk supplemented with chia seed oil compared with control. Furthermore, there has been an increase in natural antioxidants (total phenolic and total flavonoid contents) levels in the supplemented ice milk samples as compared to control. Furthermore, an increase in the shelf life of the supplemented ice milk samples was also noticed. Generally, fortification of ice milk with chia seed oil increased the concentration of omega- 3 fatty acids and also improved the antioxidant properties of ice milk.
\end{abstract}

\section{Keywords}

Chia Seed Oil, Omega-3 Fatty Acids, Natural Antioxidants, Ice Milk 


\section{Introduction}

Chia (S. hispanica) is derived from chian, which means sticky, found from Nahuatl. Chia has been in use since the times of Mayan and Aztec; it is a medicinal dietary plant species. Its outcome is a dry indehiscent fruit which is mainly known as seed. In present times, there exists a cumulative consideration and dispersal of the seeds of the plant for the advantages and uses in cookery. The seeds are known as the very rich foundation of nutrients, first of all, the polyunsaturated omega-3 fatty acids which secure your health from inflammation, advance the reasoning presentation and decrease the level of cholesterol. Additionally, sugars founded fibers which exist at high attentiveness level, are linked with decreasing inflammation, dropping cholesterol and adaptable bowel functions which eventually lead to healthy life. This appraisal recapitulates the present information on the photochemistry and pharmacological characteristics of the seeds of chia plant, with special stress on the nutritious and phytochemical examination of the plant, as well as the newly industrialized metabolomics studies [1].

Chia generates $25 \%-40 \%$ consumption of fat oil [2]. The United States Department of Agriculture (USDA) reported that chia grains consist of $42.1 \%$ direct carbon dioxide, $34.4 \%$ of total food fiber, $30.7 \%$ lipids, $16.5 \%$ fat, $5.8 \%$ moisture and $4.8 \%$ ash [3]. Nevertheless, it consists of a large amount of calcium, phosphorus, potassium and magnesium $(335-860 \mathrm{mg} / 100 \mathrm{~g})$, which are lower in sodium, iron and zinc levels (4.58 - $16 \mathrm{mg} / 100 \mathrm{~g})$ [3].

Chia is commonly eaten in order to preserve safe serum lipids in phenol acids, for various health benefits. While the availability of active ingredients present in chia seed adds to the health benefits, safety and efficacy of this therapeutic food or natural product must be medically verified since there are still limited studies in the safety of chia seed and no conclusive results published. Recent studies showed that chia (S. hispanica), which offers proteins, magnesium, phosphorus and essential fatty acids, is a remarkably complete nutritional source, e.g., De Falco et al., [4] studies had shown that ingestion of $25 \mathrm{~g}$ per day in the plasma of milled chia seed relative to whole chia seed during the 10 weeks by overweight women increased the plasma concentration of acid ALA and eicosapentaenoic acid (ESPA). The study evaluated the efficacy of milled and entire chia seed in the use of a metabolomics approach to change disease risk factors for overweight postmenopausal women.

Recently, Mobley et al., [5] had shown that diverticular disease risks are substantially decreased with increased dietary fiber intake. Depending on the source of fiber, the association with diverticular disease risk varied and cereal and fruit fiber reduced risk. A traditional view of fiber research gives insight into the evolution of fiber protection and the potential role of the fiber research of the future. Epidemiological evidence subsequently revealed that low consumption of fibers, like in rural Africa, is associated with many chronic conditions prevalent in the West but not in populations where fiber intakes are large. Such data also suggested that cereal fibers, among other factors, may have a protective effect on heart disease, cancer, metabolic disorder and obesity. Although in the early 
phase of discovery, the proposed mechanisms for fiber role in health were simplistic, the key fiber hypothesis generated interest and prompted further research into the health role of fiber, which continues today [6].

The chia's main fats are $\alpha$-linolenic acid (ALA) and linoleic acid (LA), with a smaller numbers of (saturated fatty acids), oil (omega-9), and stearic (saturated) acids. The most popular lipids are a $\alpha$-linolenic acid. ALA and LA are the two only essential fatty acids which individuals have to put into their diet, as they cannot be synthesized by their bodies [7]. For chia, ALA, fatty acids are approximately $60 \%$, LA is about $20 \%$. ALA is a source of many benefits, as well as the correlation of cardiovascular and neurological health [8], to the long-chain Omega-3 fatty acids DHA and Eicosatetraenoic (EPA).

Indeed, the amino acid content of the protein is complete. Chia, however, cannot be used as the principal protein source since Lysin is not sufficient in the crop. Chia often contains larger fiber in proportion to approximately 1:5 than other grains of soluble and insoluble fiber. The protein content of Antioxyglycerides is higher than that of many other grains [2] [9]. In addition, chia seeds are also used in the preparation of cake for example as healthy supplements with oil, and can be used in beverages, cereal and salads [10]. Chia seeds in bread products at a value of no more than 5 per cent, including breakfast, cookies, fruit juices and yogurt, have already been permitted in the European Committee [11].

The seeds of chia contain high fiber content (18 - $30 \mathrm{~g} / 100 \mathrm{~g})$. Iglesias-Puig and Haros [12] reported that their use can encourage proper intestinal functioning, reduce the level of blood cholesterol and glucose due to the use of chia seed. Such fatty acids are responsible for the effective functioning of the vision, cardiovascular diseases, cancer, autoimmune and inflammatory diseases, and also for prevention. These fatty acids are not only nutritionally important for health, but also helpful to people with heart disease, and diabetes [13].

Ice milk is a term used in the USA to refer to a standardized frozen dessert class with a fat content between 2\% and 8\% [14]. In Egypt and according to the Egyptian Standard 1185-3/2005, the fat content of ice milk must not less than 3\% [15].

Ice milk has been consuming as a dairy product all over the world. Its first definition designated it as food system known as polyphasic. The products including ice crystals, air bubbles, protein, hydrocolloid constructions, a cry concerted aqueous stage, combined and emulsified fat, protein and salts, in this sense ice milk must be described as oil-in -water suspension [16]. This paper aimed to use chia seed oil as fat substitute in formula of ice milk to augment the attentiveness of omega- 3 fatty acids and natural antioxidants of ice milk and investigated the effect of this replacement on the quality characteristics and sensory evaluation at different concentrations of chia seed oil compared with control 100\% milk fat.

\section{Materials \& Methods}

\subsection{Sources of Ingredients}

The skim milk powder, sugar, milk fat, cremodan, and chia seeds were pur- 
chased from the local market. The usage of chemical in this examination were HPLC grade and obtained from Sigma Aldrich, St. Louis, Mo, USA.

\subsection{Oil Abstraction from Chia Seeds}

The oil has been mined from chia seeds along with n-hexane by means of the labelled technique by [17].

\subsection{Proximate Analysis of Chia Seeds}

A.O.A.C [17] stated a procedure which was used to analyze directly. Chia seeds (5 grams) are used by means of jar and oven drying at $105^{\circ} \mathrm{C}$, to assess the moisture of the ingredients up to continued weight. The ash content was determined by ashing for 3 hours at $550^{\circ} \mathrm{C}$. Kjeldah method was used to understand the components of protein. Intakes and therefore the fat is reinforced by Soxhlet approximation strategies in the crude fibers of the samples. All fortitudes are three times washed away.

\subsection{Preparation of Ice Milk Supplemented with Chia Seed Oil}

Similarly, milk fats were partially substituted for $10 \%, 20 \%, 30 \%$ and $40 \%\left(\mathrm{~T}_{1}, \mathrm{~T}_{2}\right.$, $\mathrm{T}_{3}$ and $\mathrm{T}_{4}$ ). The regulatory body involved ice milk organized out of $100 \%$ milk fat. All ice milk was contained by $11 \%$ SNF, $10 \%$ fat milk, $13 \%$ sugar and $0.5 \%$ cremodan, for $1 \mathrm{~min}$, aged at $4^{\circ} \mathrm{C}$ for $16 \mathrm{~h}$. At 0,15 and 30 days of the set, quality and sensual assessment were resolute.

Control: 100\% Milk Fat.

$\mathrm{T}_{1}: 90 \%$ Milk Fat and 10\% Chia Oil.

$\mathrm{T}_{2}: 80 \%$ Milk Fat and 20\% Chia Oil.

$\mathrm{T}_{3}: 70 \%$ Milk Fat and 30\% Chia Oil.

$\mathrm{T}_{4}: 60 \%$ Milk Fat and 40\% Chia Oil.

\subsection{Physicochemical Assets of Chia Seed Oil and Ice Milk Examples}

Chia seed oil was characterized for color remained resolute on a Lovibond Tintometer (Tintometer Corporation, Salisbury, England), refractive index, acid value, peroxide value, iodine number, saponification number and, unsaponifiable matter were resolute rendering to [17]. The $\mathrm{pH}$ values of ice milk samples were measured using a digital $\mathrm{pH}$ meter in accordance with the technique designated in [17]. Overrun of ice milk samples was calculated using a standard 100 $\mathrm{ml}$ cup according to [18].

\subsection{Oily Acid Profile of Chia Seed Oil and Ice Milk Models}

Fatty acid profile of samples (chia seed oil and ice milk) were resolute by transforming fat to fatty acid methyl esters by responding $50 \mathrm{mg}$ fat with $2 \mathrm{~mL}(15 \%$ methanolic $\mathrm{HCl}$, Fluka) at $100^{\circ} \mathrm{C}$ for 1 hour. The sample tubes have been chilled in room temperature, and added $2 \mathrm{~mL}$-hexane and deionized water, then vor- 
texed at $500 \times \mathrm{g}$ for 2 minutes. After 15 minutes, the test tubes were permitted to take their position. Thereafter, supernatant was carried into GC vials, that were vaccinated to GC-MS (7890 A GC System Agilent) fitted MSD detector, by means of ZB-5 bonded silica capillary column (Zebron Phenomenex, 30 $\mathrm{m} \times 0.25 \mathrm{~mm}$ ) [19]. Fatty acids were recognized and enumerated with the help of FAME 37 Kit, Sigma-Aldrich, Chemical Company.

\subsection{Total Phenolic Contents}

Total phenolic ingredients of chia seed oil ice milk samples have been resolute according to [20]. Caffeic acid was obliged as a characteristic multifarious for the groundwork of the standardization curve.

\subsection{Total Flavonoid Contents}

Entire flavonoid ingredients of chia seed oil and ice milk were resolute rendering by colorimetric technique using rutin as standard [21]. $\mathrm{AlCl}_{3}$ (2\% solution) was equipped in methanol, then $0.5 \mathrm{~mL}$ of sample was mixed with $0.5 \mathrm{~mL}$ of $\mathrm{AlCl}_{3}$, and then incubated at room temperature for total 1 hour. The optical density has been measured at $420 \mathrm{~nm}$. All flavonoid contents were measured by the following formula and reported as quercetin equivalent (ppm). Flavonoid contents $(\mathrm{mg} / \mathrm{g})=0.025 \times$ Absorbance .

\subsection{Sensory Evaluation of Ice Milk Samples}

Sensual assessment of ice milk supplemented along with chia seed oil by twenty panelists and statistical analyzed was performed by following the method according to [22].

\subsection{Statistical Analysis}

A minimum of three replications for every sample were performed with each test. The averages and variance were calculated by statistical analysis using SPSS program.

\section{Results and Discussion}

\subsection{Proximate Analysis of Chia Seed}

Chia seed has been originated to encompass $6.45 \%$ moisture, $3.90 \%$ ash, $28.33 \%$ protein, $37.53 \%$ oil, and $35.45 \%$ dietary fiber. The Chia seed components have greater ash elements with a higher number of assets. The benefits of chia seeds such as calcium, phosphorus and copper are higher in nutrients. Here, the food fiber allows for the lower glycemic index for the chia seed. It is the quality of chia seed, as shown in Figure 1, which saves and supports body mass control.

\subsection{Physicochemical Characteristics of Chia Seed Oil}

Table 1 shows some Physicochemical characteristics of the chia seed oil. Index of refraction of chia seed oil at $25^{\circ} \mathrm{C}$ was 1.4765 . Acidity of chia seed oil $(0.80 \%$ 


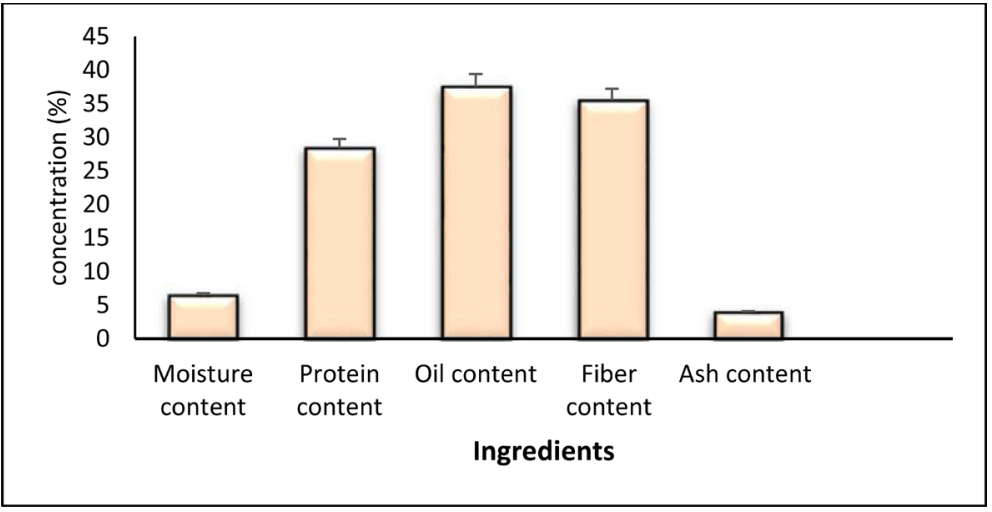

Figure 1. Proximate analysis (\%) of chia seeds. Here, the data shows the mean \pm SD values. It has the mean value of three determination.

Table 1. Some physico-chemical properties of chia seed oil.

\begin{tabular}{cc}
\hline Parameters & Chia seed oil \\
\hline Refractive index $\left(25^{\circ} \mathrm{C}\right)$ & $1.4765 \pm 0.001$ \\
Acid value $(\mathrm{mg}$. KOH/g oil) & $0.80 \pm 0.01$ \\
Peroxide value (meq. $\mathrm{O}_{2} / \mathrm{kg}$ oil) & $1.08 \pm 0.34$ \\
Iodine number (gI/100 g oil) & $206.90 \pm 8.30$ \\
Saponification value (g KOH/kg oil) & $198.60 \pm 9.00$ \\
Unsaponifiable matter $(\%)$ & $1.25 \pm 0.06$ \\
\hline
\end{tabular}

The data shall be interpreted by means of three determinations as mean \pm SD value.

as oleic acid). Oil with inferior worth of acidity is more satisfactory for consumable submissions. The peroxide rate of chia oil was (1.08 meq. $\mathrm{kg}^{-1}$ of oil). Moreover, chia oil showed higher iodine number (206.90 g I/100 g oil). Results were agreement thereupon reported by who [23]. Saponification number and unsaponifiable matter of chia oil (198.60 mg KOH/g oil and 1.25\%, respectively).

\subsection{Fatty Acid Arrangement of Chia Seed Oil}

Fatty acid arrangement of chia seed oil was recognized by gas liquid chromatography and consequently the obtained results are tabulated in Table 2. It might be noticed that carboxylic acid "linoleic acid is found to be the overriding unsaturated fatty acid in chia seed oil, which represented about (60.93\%). Carboxylic acid" hexadecanoic acid was found also to be the dominant saturated fatty acid in chia seed oils (6.81\%). These results are in contract subsequently stated by [1] [24].

\subsection{Antioxidant Content of Chia Seed Oil}

It has been observed that phenolic and flavonoid compounds are responsible for the movement of antioxidants in multiple oils of vegetable seeds; it mainly depends on the redox properties that free radicals, singlet and triplet oxygen or disintegrating peroxides must play an important role [25]. Total phenolic and flavonoid complexes (Figure 2) within the chia seed oil were (840.00 and 
Table 2. Fatty acids arrangement of chia seed oils.

\begin{tabular}{cc}
\hline Name of Fatty acids & Chia seed oil \\
\hline C14:0 & $0.03 \pm 0.0001$ \\
C16:0 & $6.81 \pm 0.31$ \\
C16:1 & $0.06 \pm 0.0001$ \\
C17:0 & $0.05 \pm 0.0001$ \\
C17:1 & $0.01 \pm 0.00$ \\
C18:0 & $4.26 \pm 0.31$ \\
C18:1 & $7.52 \pm 0.34$ \\
C18:2 & $19.88 \pm 1.16$ \\
C18:3 & $60.93 \pm 2.98$ \\
C20:0 & $0.35 \pm 0.03$ \\
C20:1 & $0.15 \pm 0.01$ \\
C22:0 & $0.08 \pm 0.001$ \\
Eicosapentaenoic acid & $1.50 \pm 0.21$ \\
Docosapentaenoic acid & $1.20 \pm 0.19$ \\
Docosahexaenoic acid & $0.73 \pm 0.11$ \\
$\Sigma$ Saturated Fatty acids & $11.45 \pm 0.71$ \\
$\Sigma$ Monounsaturated fatty acids & $7.74 \pm 0.65$ \\
$\Sigma$ Polyunsaturated fatty acids & $80.81 \pm 5.55$ \\
\hline & \\
\hline
\end{tabular}

The data shall be interpreted by means of three determinations as mean $\pm \mathrm{SD}$ value.

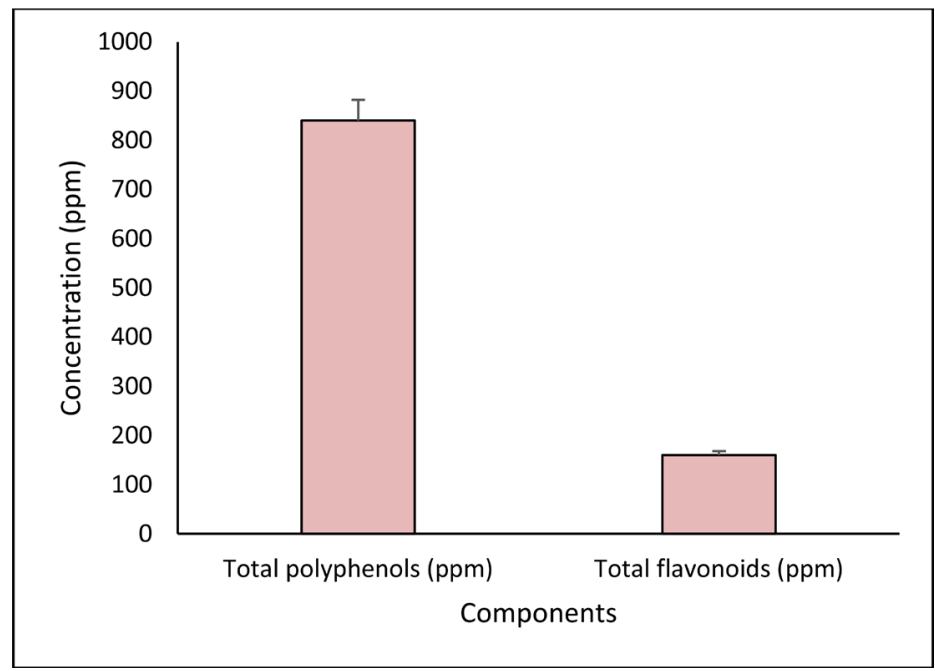

Figure 2. Antioxidants in chia seed oil. The data shall be interpreted by means of three determinations as mean \pm SD value.

$160 \mu \mathrm{g} / \mathrm{g})$, respectively.

\subsection{Some Physicochemical Assets of Ice Milk Complemented with Chia Seed Oil}

Figures 3(a)-(c) shows the Physicochemical characteristics of ice milk comple- 
mented along with various levels of chia seed oil. Statistical analysis of data shows that the fresh ice milk substitution of chia seed oil has were affected $(\mathrm{P} \leq$ 0.05 ) on ice milk $\mathrm{pH}$ value and acidity. However, the $\mathrm{pH}$ values fluctuated from 6.14 to 6.20 in terms of $\mathrm{pH}$ values (Figure 3(a)). These consequences were in contract with [26]. Acidity for expressed ice milk fluctuated from $0.29 \%$ to $0.33 \%$, the deceptive acidity of ice milk combinations was due to the milk proteins, mineral salts and dissolved carbon dioxide, and our results were in agreement with those reported by [27] (Figure 3(b)). Swarming is the terms used to designate the capacity of air combined during the chilly process. The more air added, the

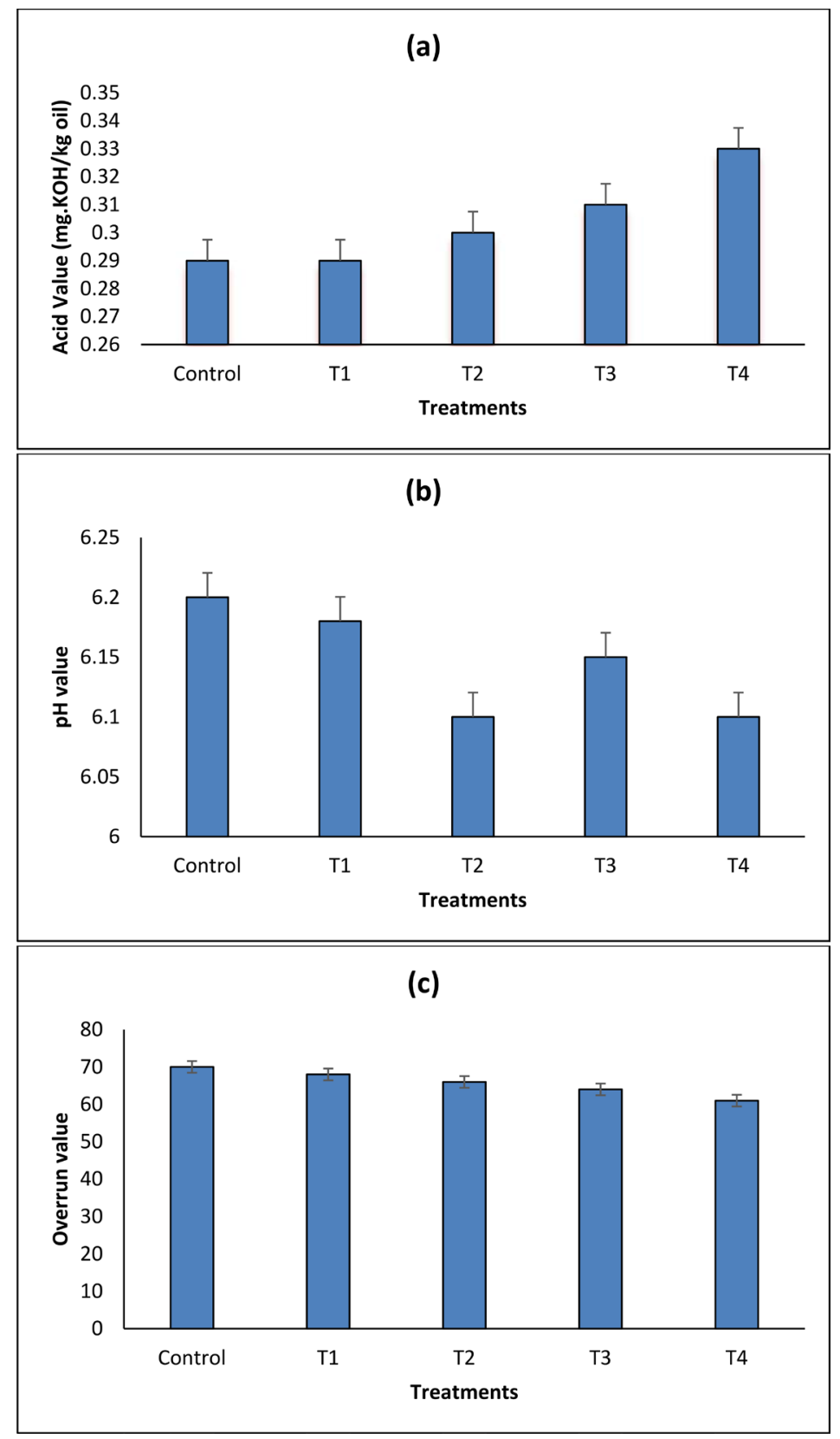

Figure 3. Ice milk supplemented with chia seed oil with physio-chemical properties. The data shall be interpreted by means of three determinations as mean \pm SD value. 
greater is the volume of ice milk produced and the advanced is the overrun. From (Figure 3(c)) it could be noticed that the highest overrun was observed with ice milk containing $10 \%$ of chia seed oil then ice milk sample containing $20 \%$ chia seed oil. Meanwhile, the lowest overrun was observed with the ice milk samples containing of $30 \%$ or $40 \%$ chia seed oil. Generally, overrun decreased slightly significantly $(\mathrm{p} \leq 0.05)$ when chia seed oil used especially at high concentrations. This result was nearly in agreement with [28]. The indistinguishable materials and dispensing conditions cannot have a significant impact on the compositional characteristics of ice cream. Those studies have suggested that unsaturated fatty acids do not have a major effect on milk quality [29]. The surplus of ice milk, with $10 \%$ and $20 \%$ chia seed oil augmented, was less than the one tested. The leakage of ice milk depends primarily on the fatty acid content of fat in ice milk [30].

\subsection{Fatty Acid Profile of Ice Milk Supplemented with Chia Seed Oil}

Table 3 includes the fatty acid profile of ice milk ice milk containing chia seed oil. Ice milk protection with chia seed oil increased attention to omega-3 fatty acids of ice milk exhibited $0.31 \%$ of linolenic acid on milk fat, while eicosatetraenoic acid, DHA was not observed on milk fat. ALA, EPA, DPA and DHA in $\mathrm{T}_{3}$ were $10.19 \%, 0.41 \%, 0.29 \%$ and $0.23 \%$, respectively, while in $\mathrm{T}_{4}$ were $13.24 \%$,

Table 3. Fatty acid profile of ice milk supplemented with chia seed oil.

\begin{tabular}{|c|c|c|c|c|c|}
\hline Name of Fatty acids & Control & $\mathrm{T}_{1}$ & $\mathrm{~T}_{2}$ & $\mathrm{~T}_{3}$ & $\mathrm{~T}_{4}$ \\
\hline $\mathrm{C} 4: 0$ & $1.38 \pm 0.04$ & $1.35 \pm 0.07$ & $1.43 \pm 0.03$ & $1.22 \pm 0.06$ & $1.19 \pm 0.10$ \\
\hline C6:0 & $2.22 \pm 0.03$ & $2.21 \pm 0.11$ & $1.67 \pm 0.06$ & $1.24 \pm 0.06$ & $1.43 \pm 0.04$ \\
\hline $\mathrm{C} 8: 0$ & $2.33 \pm 0.06$ & $2.41 \pm 0.04$ & $2.25 \pm 0.07$ & $2.14 \pm 0.02$ & $1.67 \pm 0.06$ \\
\hline $\mathrm{C} 10: 0$ & $2.47 \pm 0.13$ & $2.16 \pm 0.08$ & $2.17 \pm 0.09$ & $1.11 \pm 0.11$ & $1.45 \pm 0.03$ \\
\hline $\mathrm{C} 12: 0$ & $2.67 \pm 0.19$ & $2.36 \pm 0.12$ & $2.39 \pm 0.18$ & $2.24 \pm 0.14$ & $2.13 \pm 0.13$ \\
\hline $\mathrm{C} 14: 0$ & $10.22 \pm 0.33$ & $9.55 \pm 0.41$ & $9.58 \pm 0.41$ & $8.28 \pm 0.24$ & $8.27 \pm 0.18$ \\
\hline $\mathrm{C} 16: 0$ & $31.89 \pm 0.87$ & $31.13 \pm 0.69$ & $29.48 \pm 0.21$ & $26.94 \pm 0.66$ & $26.21 \pm 0.34$ \\
\hline $\mathrm{C} 18: 0$ & $11.35 \pm 0.41$ & $10.41 \pm 0.12$ & $9.66 \pm 0.26$ & $9.51 \pm 0.20$ & $8.56 \pm 0.32$ \\
\hline C18:1 & $22.67 \pm 0.74$ & $21.91 \pm 0.61$ & $21.26 \pm 0.22$ & $19.81 \pm 0.43$ & $18.55 \pm 0.24$ \\
\hline $\mathrm{C} 18: 2$ & $2.51 \pm 0.09$ & $2.27 \pm 0.06$ & $2.24 \pm 0.12$ & $2.18 \pm 0.14$ & $2.10 \pm 0.09$ \\
\hline $\mathrm{C} 18: 3$ & $0.81 \pm 0.05$ & $3.94 \pm 0.10$ & $6.17 \pm 0.10$ & $10.12 \pm 0.21$ & $14.24 \pm 0.27$ \\
\hline $\mathrm{C} 20: 0$ & $0.00 \pm 0.00$ & $0.10 \pm 0.001$ & $0.13 \pm 0.001$ & $0.16 \pm 0.001$ & $0.2 \pm 0.001$ \\
\hline C20:1 & $0.00 \pm 0.00$ & $0.08 \pm 0.001$ & $0.12 \pm 0.001$ & $0.17 \pm 0.001$ & $0.21 \pm 0.001$ \\
\hline $\mathrm{C} 22: 0$ & $0.00 \pm 0.00$ & $0.07 \pm 0.001$ & $0.11 \pm 0.001$ & $0.15 \pm 0.001$ & $0.20 \pm 0.001$ \\
\hline Eicosapentaenoic acid & $0.00 \pm 0.00$ & $0.11^{`} \pm 0.03$ & $0.22 \pm 0.05$ & $0.32 \pm 0.04$ & $0.60 \pm 0.05$ \\
\hline Docosapentaenoic acid & $0.00 \pm 0.00$ & $0.10 \pm 0.01$ & $0.15 \pm 0.02$ & $0.26 \pm 0.06$ & $0.53 \pm 0.03$ \\
\hline Docosahexaenoic acid & $0.00 \pm 0.00$ & $0.11 \pm 0.02$ & $0.15 \pm 0.01$ & $0.19 \pm 0.03$ & $0.25 \pm 0.05$ \\
\hline
\end{tabular}

The data shall be interpreted by means of three determinations as mean \pm SD value. 
$0.58 \%, 0.42 \%$ and $0.31 \%$, respectively. Previous studies had found that the fatty acid profile of fats and oils is significantly impacted by the amalgamation of milk fats and vegetable oils [31]. Unfinished milk fat replacement with flaxseed oil enhanced attention to desirable unsaturated fatty acids [32]. Omega-3 fatty acids have been recognized as cardiac, hepatic, anti-inflammatory, brain and eye designers. Seed oil from chia that open new boulevards for cumulative food value. Through various food substances, it could be used as an excellent source of omega- 3 fatty acids. The omega- 3 and six fatty acids ratio can be composed by omega- 3 enriched oil in the diet. Nevertheless, this needs more thorough scrutiny. The oxidative stability of fat-based products is extremely important to consider throughout the enhancement of their nutritional value. Foods that use unsaturated fatty acids more carefully are susceptible to autoxidation. The attendance of natural antioxidants (phenolic and flavonoids) in chia seed oil professionally reserved the collapse of fatty acids into food stuffs [33].

\subsection{Shelf Life of Ice Milk Supplemented with Chia Seed Oil}

Consequences of shelf life of ice milk further with chia seed oil are given in Figure 4(a) \& Figure 4(b). The acidity of all ice milk treatments ranged from 0.08 to $0.12 \%$ on the first day of storage. The acidity of ice milk samples gradually

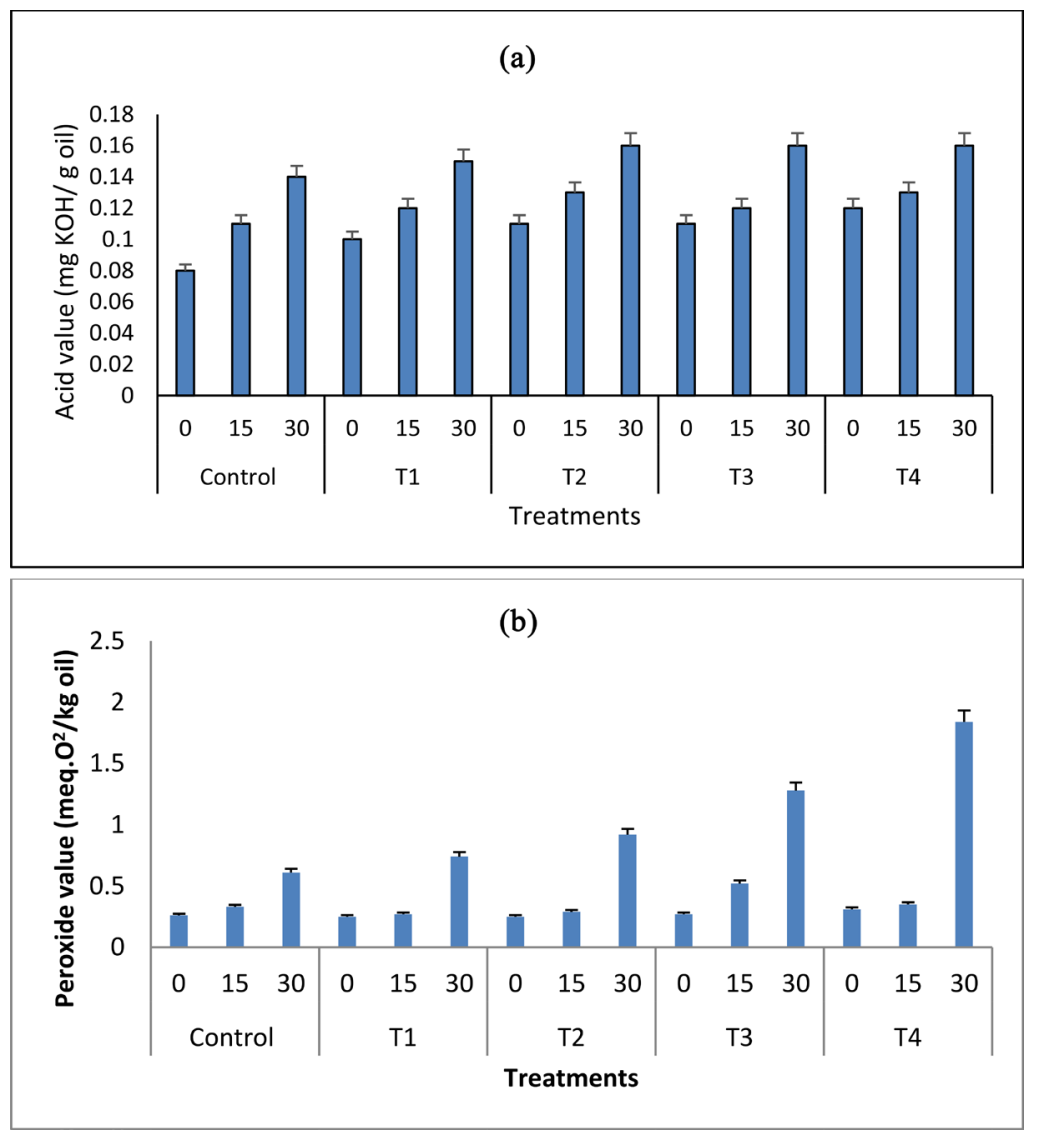

Figure 4. Quality of ice milk supplemented with chia seed oil. The data shall be interpreted by means of three determinations as mean \pm SD value. 
augmented throughout the storage period (30 days). On $30^{\text {th }}$ day of storage, acidity of control and $\mathrm{T}_{4}$ were $0.15 \%$ and $0.17 \%$, correspondingly $(P>0.05)$. Acidity of ice milk complemented with numerous heights of chia seed oil was fewer than permissible boundary of $0.2 \%$. Throughout the storing time, peroxide value has been documented. For the $T_{2}$ treatment, the storage period was not significant as the peroxide value. After 30 days of storage, additional control and other conduits were oxidized by $\mathrm{T}_{3}$ and $\mathrm{T}_{4}$. The uppermost peroxide of 1.84 (meqO $\mathrm{O}_{2} / \mathrm{kg}$ ) was experiential in $\mathrm{T}_{4}$ after 30 days of storage, which is slightly less than $10 \mathrm{MeqO}_{2} / \mathrm{kg}$, permissible limit.

\subsection{Antioxidant Ingredients of Ice Milk Complemented with of Chia Seed Oil}

Total phenolic ingredients of ice milk $\mathrm{T}_{4}$ samples were recorded $0.13,30.13$, $50.44,80.32$ and $120.22 \mathrm{ppm}$, respectively. Also, entire flavonoid content of ice milk $\mathrm{T}_{2}$ samples was noted as $0.10,8.20,14.21,20.15$ and $30.00 \mathrm{Ppm}$, respectively (Figure 5(a) \& Figure 5(b)). A higher absorption of free radicals can cause other damaging effects including atherosclerosis, arthritis and cancer in human bodies [34]. Certain documents have shown that pharmacological and organic action takes subordinate metabolites of plants in contradiction of oxidative pressure, cancer, accelerated ageing and thermogenesis [35]. Total phenolic and flavonoid foragers of many exposure oxygen forms are extremely involved.
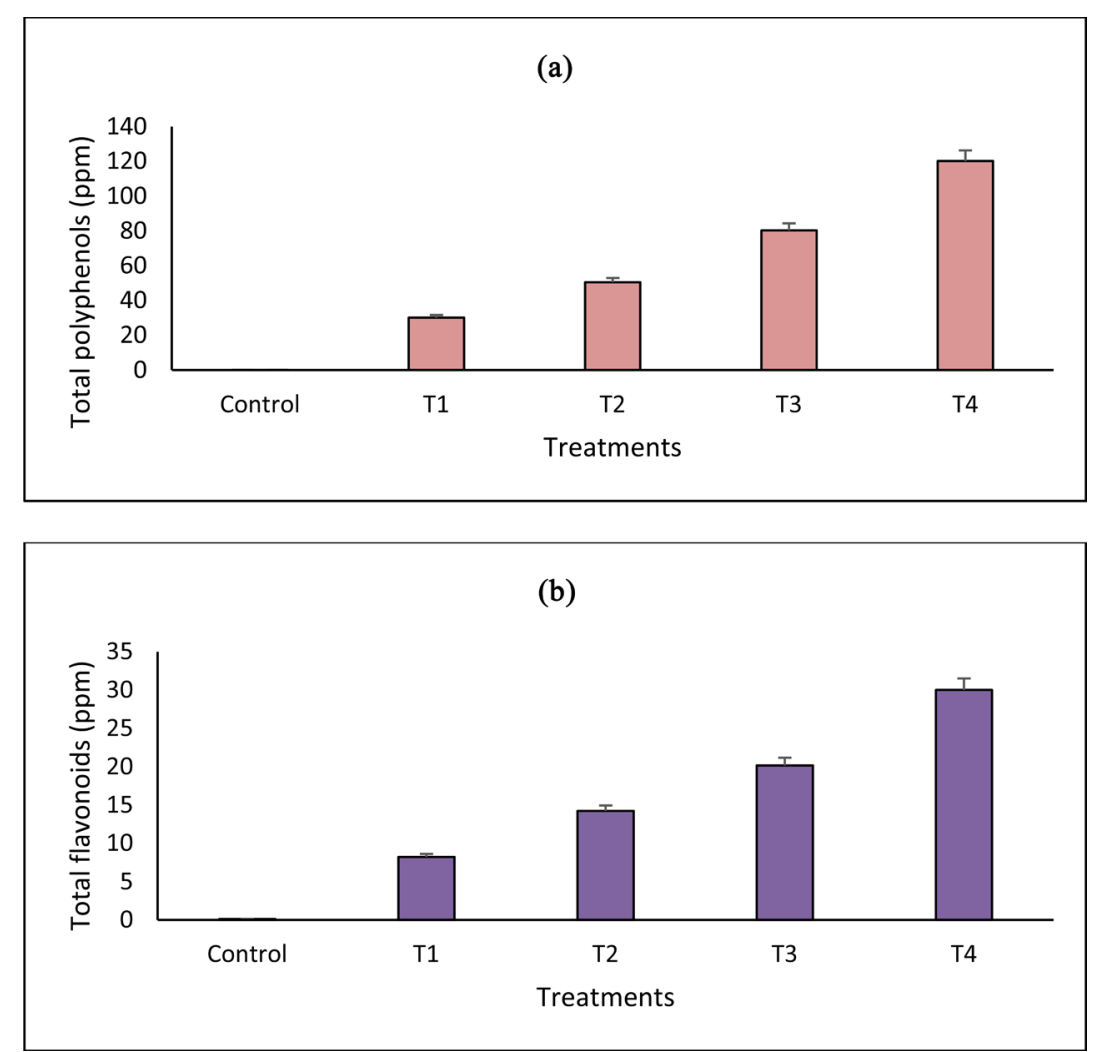

Figure 5. Antioxidant content of ice milk supplemented with chia seed oil. The data shall be interpreted by means of three determinations as mean \pm SD value. 


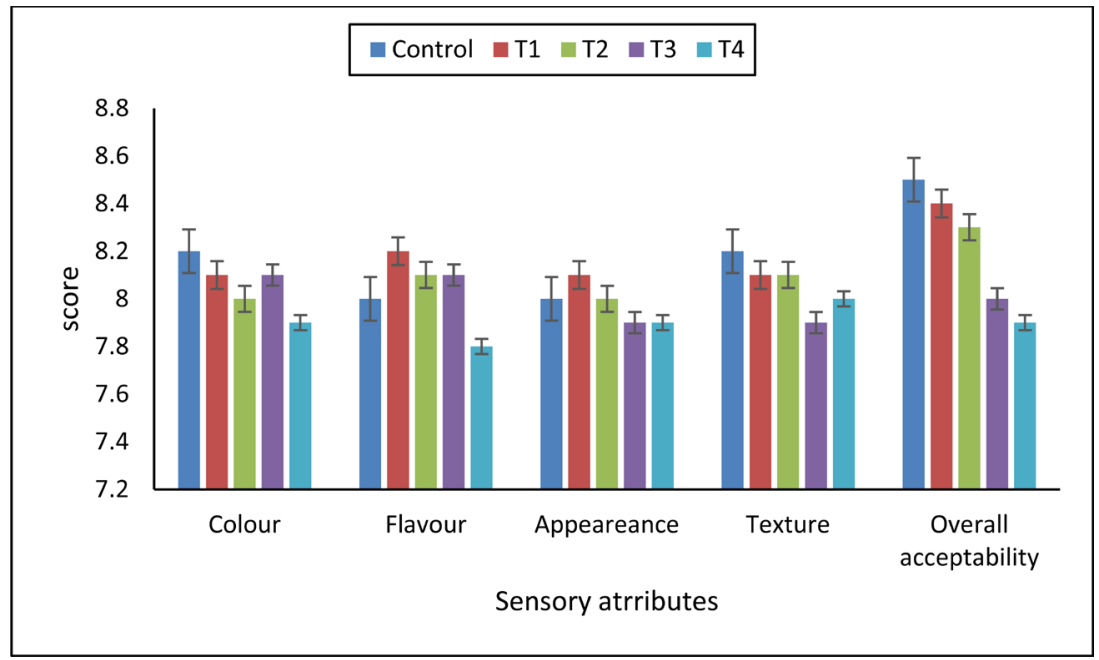

Figure 6. Sensual assessment of ice cream complemented with chia seed oil. Data are expressed as mean \pm SD values given represent means of three determinations.

\subsection{Sensual Assessment of Ice Cream Complemented with of Chia Seed Oil}

Organoleptic properties of food products are important monitoring methods which indicate the food acceptability to consumers. Consequences of sensual assessment of ice milk complemented with chia seed oil have been obtainable in Figure 6. Calculation of chia seed oil did not have any influence on color, flavor, texture, appearance and overall acceptability of fresh ice cream. Color, flavor texture and appearance and general suitability score were non-significant up to 30 days of storing period. After 30 days, sensual score worsened and weakening in sensual score was not due to the accumulating of chia seed oil somewhat it was due to the corrosion of unsaturated fatty acids.

\section{Conclusions}

Nutritional Chia delivers an array of pharmacological possessions, though comprehension of the nature of bioactive and fatty acids accountable for its biological activity by means of mechanistic methods in cell and mammal replicas is a precondition prior to its therapeutic practice.

Fortification of ice milk with chia seed oil meaningfully enhanced the attentiveness of omega-3 fatty acids in ice milk, Likewise antioxidant contents of supplemented ice milk were greater than control (only containing milk fat). Besides, protection of chia seed oil enhanced the ledge life of ice milk samples; the advanced skills to defend omega-3 supplemented dairy foodstuffs by means of satisfactory research and wrapping are wanted. The best overall acceptability was found with control sample followed by $\mathrm{T}_{1}$ (containing $10 \%$ chia seed oil) and $\mathrm{T}_{2}$ (containing 10\% chia seed oil) samples. Technologically, additional investigation should be directed which would operate the chia seed oil for the expansion of purposeful foods, or medicinal, pharmaceutical and other non-food industrial requests. 


\section{Conflicts of Interest}

The authors declare no conflicts of interest regarding the publication of this paper.

\section{References}

[1] Crowe, F.L., Balkwill, A., Cairns, B.J., Appleby, P.N., Green, J., Reeves, G.K., Key, T.J. and Beral, V. (2014) Source of Dietary Fibre and Diverticular Disease Incidence: A Prospective Study of UK Women. Gut, 63, 1450-1456. https://doi.org/10.1136/gutjnl-2013-304644

[2] Cassiday, L (2016) Sink or Swim: Fish Oil Supplements and Human Health. Inform, 27, 6-13. https://doi.org/10.21748/inform.04.2016.06

[3] Coelho, M.S. and Salas-Mellado, M.M. (2015) Effects of Substituting Chia (Salvia hispanica L.) Flour or Seeds for Wheat Flour on the Quality of the Bread. LWT_Food Science and Technology, 60, 729-736. https://doi.org/10.1016/j.lwt.2014.10.033

[4] De Falco, B., Amato, M. and Lanzotti, V. (2017) Chia Seeds Products: An Overview. Phytochemistry Reviews, 16, 745-760. https://doi.org/10.1007/s11101-017-9511-7

[5] Mobley, A.R., Jones, J.M., Rodriguez, J., Slavin, J. and Zelman, K.M. (2014) Identifying Practical Solutions to Meet America's Fiber Needs: Proceedings from the Food \& Fiber Summit. Nutrient, 6, 2540-2551. https://doi.org/10.3390/nu6072540

[6] Mohammed, G.M. and Basuny, A.M. (2020) Chia Seed Oil a New Source of Omega-3. Plant Archives, 20, 2678-2683.

[7] Mohd, A.N., Yeap, S.K., Yong, H.W., Beh, B.K., Wei, T.S. and Guan, T.S. (2012) The Promising Future of Chia, Salvia hispanica L. Journal of Bio-Medical and Biotechnology, 2012, Article ID: 171956. https://doi.org/10.1155/2012/171956

[8] Nieman, D.C., Gillitt, N., Jin, F., Henson, D.A., Kennerly, K., Shanely, A., Ore, B., Su, M.M. and Schwartz, S. (2012) Chia Seed Supplementation and Disease Risk Factors in Overweight Women: A Metabolomics Investigation. Journal of Alternative and Complementary Medicine, 18, 700-708. https://doi.org/10.1089/acm.2011.0443

[9] Valdivia-López, M.Á. and Tecante, A. (2015) “Chia (Salvia hispanica): A Review of Native Mexican Seed and Its Nutritional and Functional Properties. Advances in Food and Nutrition Research, 75, 53-75. https://doi.org/10.1016/bs.afnr.2015.06.002

[10] Borneo, R., Aguirre, A.E. and León, A. (2010) Chia (Salvia hispanica L.) Gel Can Be Used as Egg or Oil Replacer in Cake Formulations. Journal of the American Dietetic Association, 110, 946-949. https://doi.org/10.1016/j.jada.2010.03.011

[11] Attalla, N.R. and El-Hussieny, E.A. (2017) Characteristics of Nutraceutical Yoghurt Mousse Fortified with Chia Seeds. International Journal of Environment, Agriculture and Biotechnology, 2, 2033-2046. https://doi.org/10.22161/ijeab/2.4.61

[12] Iglesias-Puig, E. and Haros, M.M. (2013) Evaluation of Performance of Dough and Bread Incorporating Chia (Salvia hispanica L.). European Food Research and Technology, 237, 865-874. https://doi.org/10.1007/s00217-013-2067-X

[13] Djordjevic, A., Spasic, S., Jovanovic-Galovic, A., Djordjevic, R. and Grubor-Lajsic, G. (2004) Oxidative Stress in Diabetic Pregnancy: SOD, CAT and GSH-Px Activity and Lipid Peroxidation Products. The Journal of Maternal-Fetal \& Neonatal Medicine, 16, 367-372. https://doi.org/10.1080/jmf.16.6.367.372

[14] Tharp, B.W. and Young, L.S. (2013) An Encyclopedic Guide to Ice Cream Science and Technology. DES Tech Publications, Inc., Lancaster, 183. 
[15] Soad, H., Mehriz, A. and Hanafy, M. (2014) Quality Characteristics of Ice Milk Prepared with Combined Stabilizers and Emulsifiers Blends. International Food Research Journal, 21, 1609-1613.

[16] Cruz, A.G., Antunes, A.E., Sousa, A.L.O., Faria, J.A. and Saad, S.M. (2009) Ice-Cream as a Probiotic Food Carrier. Food Research International, 42, 1233-1239.

https://doi.org/10.1016/j.foodres.2009.03.020

[17] A.O.A.C. (2016) Association of Official Analytical Chemist. Official Methods of Analysis. 19th Edition, Washington DC.

[18] Marshall, R.T. and Goff, D. (2003) Formulating and Manufacturing Ice Cream and Other Frozen Desserts: Frozen Desserts: Formulating, Manufacturing, and Marketing. Food Technology (Chicago), 57, 32-45. https://doi.org/10.1007/978-1-4615-0163-3 13

[19] Qian, M. (2003) Gas Chromatography, Food Analysis Laboratory Manual. Kluwer Academic Publishers, New York. https://doi.org/10.1007/978-1-4757-5250-2 18

[20] Gutfinger, T. (1981) Polyphenols in Olive Virgin Oils. Journal American Oil Chemical Society, 58, 996-998. https://doi.org/10.1007/BF02659771

[21] Nile, S.H. and Khobragade, C.N. (2010) Antioxidant Activity and Flavonoid Derivatives of Plumbago Zeylanica. Journal of Natural Products, 3, 130-133.

[22] Lebesi, D.M. and Tzia, C. (2011) Effect of the Addition of Different Dietary Fiber and Edible Cereal Bran Sources on the Baking and Sensory Characteristics of Cupcakes. Food and Bioprocess Technology, 4, 710-722.

https://doi.org/10.1007/s11947-009-0181-3

[23] Ixtaina, V.Y., Martínez, M.L., Spotorno, V., Mateo, C.M., Maestri, D.M. and Diehl, B.W.K. (2011) Characterization of Chia Seed Oils Obtained by Pressing and Solvent Extraction. Journal of Food Composition and Analysis, 24, 166-174.

https://doi.org/10.1016/j.jfca.2010.08.006

[24] El-Beltagi, H.S., Salama, Z.A. and El-Hariri, D.M. (2007) Evaluation of Fatty Acids Profile and the Content of Some Secondary Metabolites in Seeds of Different Flax Cultivars (Linum usitatissimum L.). General Applied Plant Physiology, 33, 187-202.

[25] Osawa, T. (1994) Novel Natural Antioxidant for Utilization in Food and Biological Systems. Postharvest Biochemistry of Plant Food-Materials in the Tropics. Japan Scientific Societies Press, Tokyo.

[26] El-Sheshetawy, H.E., Mossad, A., El-Helew, W.K. and Farina, V. (2016) Comparative Study on the Quality Characteristics of Some Egyptian Mango Cultivars Used for Food Processing. Annals of Agricultural Sciences, 61, 49-56. https://doi.org/10.1016/j.aoas.2016.04.001

[27] Lim, C.W., Norziah, M.H. and Lu, H.F.S. (2010) Effect of Flaxseed Oil towards Physicochemical and Sensory Characteristic of Reduced Fat Ice Creams and Its Stability in Ice Creams upon Storage. International Food Research Journal, 17, 393-403.

[28] Corradini, S.A.S., Madrona, G.S., Visentainer, J.V., Bonafe, E.G., Carvalho, C.B. Roche, P.M. and Prado, I.N. (2014) Sensorial and Fatty acid Profile of Ice Cream Manufactured with Milk of Crossbred Cows Fed Palm Oil and Coconut Fat. Journal of Dairy Science, 97, 6745-6753. https://doi.org/10.3168/jds.2014-8290

[29] Nadeem, M., Hussain, I. and Abdullah, M. (2013) Effect of calcium salts of soybean oil fatty acids on physical and chemical characteristics of milk in cows. Indian J. Anim Sci., 83, 811-814.

[30] Gonzalez, S., Duncan, S.S.E., Keefe, S.F.O., Sumner, S.S. and Herbein, J.H. (2003) Oxidation and Textural Characteristics of Butter and Ice Cream with Modified Fat- 
ty Acid Profiles. Journal of Dairy Science, 86, 70-77. https://doi.org/10.3168/jds.S0022-0302(03)73585-1

[31] Arif, A.M., Javed, I., Abdullah, M., Imran, M., Mahmud, A., Nadeem, M. and Ayaz, M. (2016) Chemical Characteristics of Mango (Mangifera indica L.) Kernel Oil and Palm Oil Blends for Probable Use as Vanaspati. Journal of Oil Palm Research, 28, 344-352. https://doi.org/10.21894/jopr.2016.2803.10

[32] Van Aken, G.A., Ten, G.E., Van Iangevelde, A.J. and Schenk, H. (1999) Composition and Crystallization of Milk Fat Fractions. Journal of the American Oil Chemists' Society, 76, 1323-1331. https://doi.org/10.1007/s11746-999-0146-8

[33] Azeem, M.W., Nadeem, M. and Ahmad, S. (2015) Stabilization of Winterized Cottonseed Oil with Chia (Salvia hispanica L.) Seed Extract. Journal of Food Science and Technology, 52, 7191-7199. https://doi.org/10.1007/s13197-015-1823-2

[34] Adesegun, S.A., Elechi, N.A. and Coker, H.A.B. (2008) Antioxidant Activities of Methanolic Extract of Sapium Elliticum. Pakistan Journal of Biological Sciences, 11, 453-457. https://doi.org/10.3923/pjbs.2008.453.457

[35] Borneo, R., Leon, A.E., Aguirre, A., Ribotta, P. and Cantero, J.J. (2009) Antioxidant Capacity of Medicinal Plants from the Province of Cordoba (Argentina) and Their in Vitro Testing in a Model Food System. Food Chemistry, 239, 70-76.

https://doi.org/10.1016/j.foodchem.2008.06.027 